\title{
The influence of psychosocial adjustment factors on team embeddedness at the workplace
}

\section{Rashid Shar Baloch*}

\section{SAAF SINDH,}

Plot 82, Gymkhana, Tando Allahyar, Sindh, Pakistan

Email: rashidsharr@gmail.com

Email: rashidsharr@iCloud.com

*Corresponding author

\section{Ramsha Ali Baloch}

Dow University of Health Science Ojha - DUHS,

Karachi, Pakistan

Email: ramshart6@gmail.com

\section{Asfandyar Ali Baloch}

National University of Modern Languages (NUML),

Hyderabad Campus, Sindh, Pakistan

Email: balochasfandyar@gmail.com

\section{Sheeraz Ali Yousafzai \\ Public Administration Department, Faculty of Social Sciences, University of Sindh, Jamshoro, Pakistan Email: Sherazk052@gmail.com}

\begin{abstract}
The high prevalence of aggression, anxiety and stress symptoms among team members in the organisation, while acquisition of task is alarming causation of adjustment disorder influences on team embeddedness, is the subject of this study. The ontogenesis of psychosocial adjustment disorder in any employees is not palingenetic, this is exact reproduction of psychosocial factors (PSF) which develops at workplace The most important strategy for productivity improvement is based on the fact that human productivity, both positive and negative, is determined by the attitudes of all those who work in the enterprise and gap surfaced between teamwork and competence development particularly with regard to managing individualism within organisation and specifically individualistic approach, organisational justice, productivity management and psychosocial support. We strongly feel that there is a need to reexamine organisational team credentials and possible strong influences on individual's psychosocial adjustment disorders. Findings suggest psychosocial adjustment factors are significantly correlated with psychosocial disorders (PSDs).
\end{abstract}


Keywords: team embeddedness; individualistic approach; psychosocial adjustment factors; teamwork adjustment.

Reference to this paper should be made as follows: Baloch, R.S., Baloch, R.A., Baloch, A.A. and Yousafzai, S.A. (2019) 'The influence of psychosocial adjustment factors on team embeddedness at the workplace', Int. J. Management Concepts and Philosophy, Vol. 12, No. 3, pp.312-328.

Biographical notes: Rashid Shar Baloch is an Eminent Social and Organisational Scientist, working for social awareness and cognitive development among employees in general and public in particular. He holds a $\mathrm{PhD}$ degree in Public Administration with expertise in sociological theory, organisation and social theory, quantitative as well as qualitative social research. He has authored some books on management, industrial relations, organisational psychology, HFE and other socio-economic topics. $\mathrm{He}$ is an independent researcher with keen interest in organisational psychology, human factors engineering and working for social welfare and knowledge development of deprived people. His research work has previously been published in International Strategic Management Review (SMR), European Scientific Journal (ESJ), Int. J. Work Organization and Emotion, Grassroots and several other domestic journals.

Ramsha Ali Baloch is an innovative and independent research scholar. Her motive is to study in the area of peoples' efficiency and comfort in the organisational and domestic working environment, working to make people conscious of their body postures. She has practitioner skills in orthopaedic and neuro-musculoskeletal diagnosis, treatment and management of the client. Her current research interests include the ergonomics, psychosocial disorder relationship with physical strain and sprain, history of medical physiotherapy reforms, literacy studies and the impact of teaching and academic policies. She is affiliated with the Department of Physiotherapy (DPT) of the Dow University of Health Sciences (DUHS), Pakistan.

Asfandyar Ali Baloch obtained his BS (Hons) in Linguistic and Literature at the National University of Modern Languages (NUML), Hyderabad Campus, Sindh, Pakistan. His current research interests include the history of philosophy, music education, social and physical ethics, literacy studies and the impact of career choices on society. He teaches philosophy, linguistic and literature and literacy theory.

Sheeraz Ali Yousafzai obtained his Diploma in Commerce (DCom), BS (Hons) in Accounting and Finance, MS (Hons) in Human Resource Management at the IBA, Public Administration Department, Faculty of Social Sciences, University of Sindh, Jamshoro. He has worked for over five years with school and financial institutions all across the country to support students in various fields. He has developed numerous social and welfare projects to help students and build critical thinking and communication skills.

\section{Introduction}

Adjustment disorders are more social than clinical and linked with psychological disorders. Therefore, the main argument of this study is to examine the influence, causes and associations of psychosocial adjustment disorder factors at the workplace on team 
embeddedness and measured in the acquisition of task work. We examine degree of the influence of psychosocial factors (PSF) such as negative psychosocial adjustment skills (NPAS), lack of team leader experience and qualification (NTEQ), negative teamwork embeddedness (NTEN) no competence development (NCMD), less individualism in task acquisition (LITA) on psychosocial disorder (PSD) like psychosocial adjustment disorder at workplace (PADW), psychosocial adjustment disorder in team (PADT), team conflict (TECN), and teamwork adjustment anxiety disorder (TAAD). The fact is, individual and teams represent at both the individual level and the societal level and suggest that they are extremely salient themes or patterns which people use to understand, categorise and interpret in their backdrop environment and to structure their sense of self and identity (Robert and Wasti, 2002).

Individualism with teamwork might be having an important effect on organisational culture as consequence of the fact that all organisations embedded within the societal cultures which are likely to have an ambient influence on organisations embeddedness within them (Hofstede, 1985). Proviso, we study the causes of an organisation where profits are low and products or services are of below standard, it is much likely that we can detect some psychosocial adjustment disorders within team members. It does not only impinge on the organisation efficacy but also ruins the skills and capabilities of an individual engaged or placed in such team stature, because the actively disengaged employees are not just unhappy at work while they are buys acting out their unhappiness in work places (Dhir and Shukla, 2018).

Consequently, employees more often remained psychosocially unsupported and unadjusted. Research on person-organisation fit, emphasises that the congruence between an employee's characteristics and his organisation's characteristics is desirable for both the individual and the organisation (Robert and Wasti, 2002; Rashid Ali and Yasmeen, 2011; Hofstede, 1985). The recent study by Dhir and Shukla (2018) published in Int. J. Management Concepts and Philosophy revealed that:

\begin{abstract}
"Organizational diversity is a known phenomenon in the work places and also facilitates employees through their experiences of being the part of any specific group by choice or by chance. To deal with the organizational diversity in terms of age, gender, education tenures, etc., in the fulfilment of organizational purposes we need to know the generic behavioural pattern of these groups. The popular and beneficial practices and facilities in organizations are not able to attract younger talents in work places. Employees are not ready for the simultaneous investment of their physical, emotional and cognitive energies, which leads towards disengagement of employees." (Dhir and Shukla, 2018)
\end{abstract}

Whereas, teams are not usually so unified that can immune internal conflicts like mutual distrust, misunderstandings, exasperations, exploitations, blames, personal and group clashes.

Politics in organisations is a sacrosanct fact and it has been generally believed that behaviour in and of organisations is most often political in nature (Khatri and Gupta, 2017). Such situation brought some PSDs to the extent that analogous bell's ringing is supposed to usher in the closest apocalypse of the organisation because sometimes employee could not tolerate peer pressure, lost supervisor's support, cultural clashes, social inequality and nature of interpersonal relationship which develops or cause to the development of PSDs. Employees with psychosocial adjustment disorders often have inconvenience functioning in social situations and difficulty to perform as a team player. Necessary skill set, intellectuality, process relevance, appropriate knowledge, and 
positive attitude are requirements of the management for control and success of a team to achieve the task.

\section{Literature review}

\subsection{Psychosocial functions and support}

PSF represent aspects of the work environment having to do with interactions with other people and provides two dimensions of the mentoring process that affect careers are vocational (career coaching) and psychosocial and psychosocial functions include serving as a role model, friend, and counsellor, and providing positive regard and acceptance (Silverthorne, 2015). Whereas, no gender differences in obtaining a mentor, the opportunity to have multiple mentors, close relationships with mentors, mentors' level of professional status, and the perception of career and psychosocial support received from their mentors (Barbara and Valerie, 2014). On the contrary, PSD effects can include lifestyle changes, stress on personal relationships, anger, hostility and depression. Theoretically, fit for the organisation is the subjective experience of congruence between the values that shape a person's general expectations and their perceptions of whether or not those values are represented in a specific context. Individuals have adhered to perceptions such as independence, uniqueness, and self-reliance while teams are suggestive of interdependence, belongingness to team and subservience to the demands of the team. Individuals with teams are for competitive performance and performance is based on the competence of an employee or behaviours demonstrated at workplace. As the principal resource and the central factor, the individual in organisation all have a role to play. Placing employees' in-group and telling them to work together as team to achieve common objective does not result in cooperation and teamwork because employees may still lack several people-oriented values such as listening, presenting one's own ideas, responding constructively to others, providing support, recognising the interests and achievement of others, building team charters, and managing conflicts among others (Anderson, 1990). Whilst it is also evident in our pilot study, from the interviews of 234 individuals, employed in an organisation who have affirmed that they have been reasonably (financially) rewarded but their individualist role in the team is not significantly recognised.

In such situations, the manifestation of the PSD is likely to report like adjustment disorder, maladjustment of personality, anxiety disorder and obsessive-compulsive disorder (OCD) or disease of doubts by some obsessive thoughts.

Our study is restricted to observe the relationship of PSF that effect on the PSD. A cursory examination of the pertinent literature revealed that effective team usually perform well in minimum or given time and team members fully satisfied with a task, team leader and organisational policies and have viably no stress, low turnover, and absence record (Parker and Williams, 1994). The characteristics of members of the team are very important in order to establish a relationship between team and individual. Managers must consider three types of traits in teammates in setting up a team.

1 task relevant skills

2 correct interpersonal skill 
3 a degree of diversity, i.e., personalities, gender, ethnic group, attitudes, and experience (Blackmon, 1998).

Team members also have a quality to comprehend the whole of team protean subject basically team members should be protean thinkers who can scan the horizons of work, person and society. Other factors that can unify individual and team together are similar attitudes and values, discovering common ground and develop mutual understandings. External threats, such as fierce outside competition or survival challenges, give a compelling reason for a team to pull together as an organised part of the organisation (Bartol et al., 2011) and major successes produce strong positive feelings about teammates (Mullen and Copper, 1994). Difficulty in joining a group, based on factors such as high standards, sacrifice or difficult training can build a common bond and finally size of the team can be a factor because team and individual relationships easier when group are small, and it is more difficult to achieve and maintain as team grow larger (Banister, 1992).

For the acquisition of well define task work by teamwork, the outsized group always weaken coalition functioning and seriously effects the proportion to the other work and team performance, usually complicates the task acquisition. This leads to certain discourses that later constitute a way of considerate and assessing authenticity.

As such, when some idea is construed in a particular way, when being selectively translated in favour of focusing attention on one element while others are neglected or skipped it follows that a former understanding of this idea is shaped and distorted whether intentionally or not (Aksom, 2017). Whilst, compassion plays a crucial role in modern society by creating and sustaining human communities. It demonstrates moral goodness and contributes to social as well as personal cause, in the workplace compassion is very essential because it acts prevail at all levels from leaders who transform the sufferings of the team members of an organisation and it makes people feel known and seen, and thereby, reduces loneliness among members and is associated with positive feelings, attitudes and behaviour in the workplace (Subba and Rao, 2016). As teams are prolific in the organisation, so the optimal numbers of team members always create better communication, coordination and attention among teammates and the effects have burgeoned as team members trust on the available skills, competence, resources and opportunities (Wharton, 2006).

Teammates have both the organisational citizenship behaviour (OCB) and workplace deviance behaviour (WDB). OCB demonstrates the altruism and incremental fair performance of employees; whilst the psychosocial adjustment disorder predicts WDB as employees' cognitive evaluation and judgment of the work remained unaligned and unsupported. We critically examine that work defiant behaviours and voluntary behaviours as posited by Robinson and Bennett (1995), we perceived that the deviant behaviours are intentional as a refusal of dysfunctional or flawed instructions, subjectivity on superior competency and egocentrically critiquing on unbefitting policies, rejection the processes or technologies parsimoniously considered as positive deviant. We analysed them on psychosocial adjustment disorder factors in WDB (Galperin, 2002); Whilst deviant behaviours stimulators are not limited to 'job stressors, organisational frustration, lack of control over the work environment, weak sanctions for rule violations and organiSational changes such as downsizing' [Appelbaum, (2005), p.50]. Whereas, psychosocial adjustment disorders' factors and 'workplace environment characteristics' are a strong predictor of employee's deviant workplace behaviours. 
Our study corresponds' Henle (2005) postulation of workplace deviance to person-based perspective because of the strong relationship between person-based and organisation-based types of deviances and 'workplace deviance occurs as a response to being treated inequitably in the workplace' [Appelbaum, (2007), pp.591-2].

Psychological empowerment is a prominent factor to motivate an employee for change, innovation, cooperation, teamwork and willingness to participate in the decision-making processes and pervasive influence of norms provides a means of control over what people say and do (Spreitzer, 2005). Working in teamwork become stressful due to incompetent leadership, misunderstanding, stagnancy, lack of professional autonomy, weak or faulty communication, poor time management and SOPs (Roach, 2017).

Acquisition of tasks also failed when individuals' efforts ignore and credits given to whole teams rather than an individual and conflict among teammates not resolved within adequate time and occasion. Such situations create anxiety and adjustment disorder related to the stress of teamwork failure and self-limited or disengaged behaviours of a team member. Motivation, self-efficacy, dedication, and cooperation is reflective of contextual performance which is essentially required for the collective task acquisition and when team members lack these abilities it reflects premorbid of adjustment disorders. Such psychological variables are widely considered as intervening variables and psychological scores (Jeppesen, 2006). Team effectiveness depends on the several different permutations of what individual must have and must do and respond to some unidentifiable stressors, anxiety occurs within the specific time and persist for six months even after the termination of stressors or its consequences due to adjustment disorders. However, adjustment disorder diagnoses apply only to psychological conditions that occur in response to identifiable psychosocial stressors and the influence of adjustment disorder is clinically significant but also strongly related with social, occupational and familial variables which manifested as decreased performance at work, change in social relationships causing impairment and individuals from disadvantaged life circumstances experience may be at increased risk for adjustment disorders (Association, 2013).

Whereas, disengaged behaviours stem from the previously mentioned factors stimulates the presence of comorbidity of anxiety and depression in psychosocial adjustment disorders. Apart from heterogeneous factors, social and occupational performance neglect is also a strong variable to identify the gravity of psychosocial adjustment disorders. In this study, psychosocial adjustment skills were dependent variable to gauge its effect on other psychosocial adjustment factors. Based on the above-reviewed literature, we developed the following hypotheses to assess the psychosocial adjustment factors in team embeddedness.

Hypothesis 1 Psychosocial adjustment disorder significantly correlated with PSF.

Hypothesis 2a PSF contribute more to the PADT.

Hypothesis 2b PSF contributes more to the prediction of TECN.

Hypothesis 2c PSF significantly correlated with TAAD.

Hypothesis 2d PSF contribute more to the NPAS.

Hypothesis 2e PSF contributes more to the prediction of individualistic task acquisition. 
Figure 1 SEM model (see online version for colours)

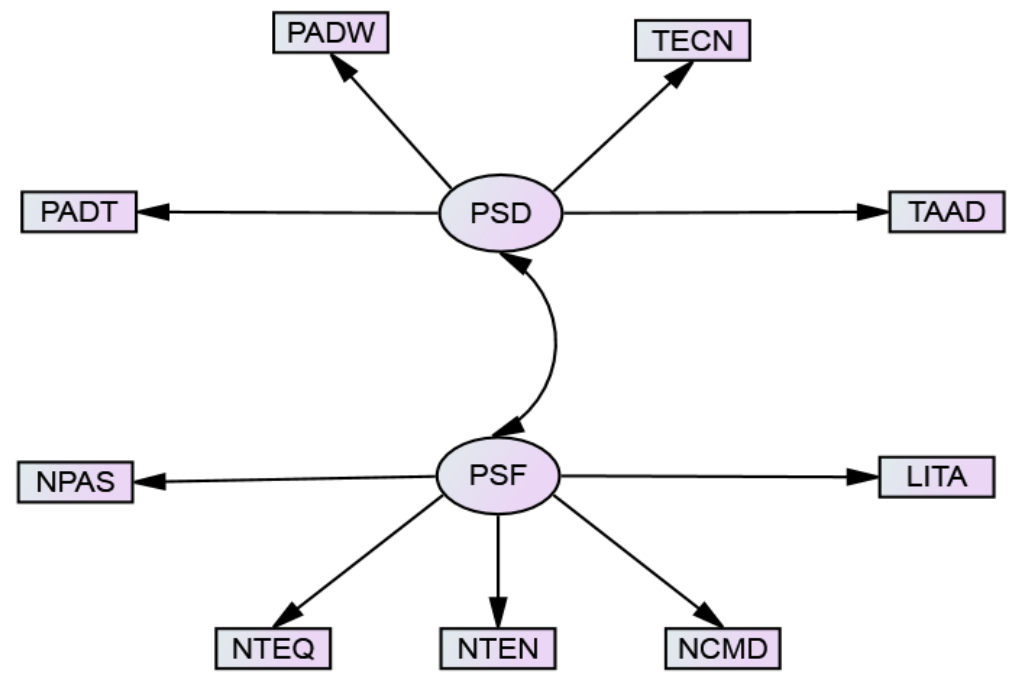

We constitute the SEM model (Figure 1) empirically verifiable for hypotheses, endogenic and exogenic variables testing to determine the PSF influence on PSD logical outcome.

\subsection{Cross-sectional designs and common method variance issues}

Self-reported data and CMV accuracy are mostly dependable on the nature of the variable. This study is based on questionnaire survey instrument and administered to the eligible participants using different method and various data source to avoid the problem of mono-method bias and our constructs measured by multiple methods to minimise any validity threat of our study (Donaldson and Grant-Vallone, 2002). We also change the anchors for the ends of the scales to get the reasonable skewed end, collect additional data and examine them simultaneously. We also employed Linacre's anchored maximum likelihood method, using the many facet Rasch model to address rater bias. We also check single factor which indicated less than $34 \%$ variances in the data $\left(\sigma^{2}=33.15\right)$ by using Harman's single-factor test, further to get more authenticity of data we employed EFA and CFA tests also, to remove any CMV issues.

\section{Material and methodology}

\subsection{Participants}

With the prior approval of the management of the concerned factories, we displayed fliers on visible location as advised by the management of the respective factory. Flier showed the purpose, schedule, eligibility criterion, voluntary nature and confidentiality assurance of the current research. We have adopted straight and simple approach to distributing/ collect data and guide participants to complete battery of questionnaire with their signature on an informed consent form. We identified 15 teams as existed in sugar factories traditionally, from the different sections of five sugar factories having the similar crushing capacity. Size of the team ranges from 4 to 12 individuals within each 
department of multiple shifts. Total participants were 643 out of which 501 selected due to clear and clean responses to the survey questionnaire. Survey questionnaire containing 49 items in an easy and understandable language known to participants and they were asked to rate using the available survey scales.

A volunteer was also assigned to help participants to avoid any mistake. Survey questionnaire distributed in the first week of April 2016 and again repeated in September 2016. On both occasion, survey activity was offered independently to employees and their participation was exclusively voluntary with their consent and management permissions within time specially reserved for this activity.

The items were equipoise for effects control and we grouped data into two factors:

1 PSF

2 PSD.

PSD factor identified four variables, PADW, PADT, TECN, and TAAD. Whereas, PSF observed five variables NPAS, lack of (negative) team leader experience and qualification (NTEQ), NTEN NCMD, and LITA. We analyse both factors to observe the outcome influence on PSD.

We also combined raw data of both survey questionnaire as the participation population scoring rate was identical on a Likert scale ranging from strongly agree (5) to strongly disagree (5). Reverse coding and variable transformation technique utilised where needed; after removing and sorting out errors, anomalies and cleaning the data, the overall response rate was $77.9 \%(\mathrm{n}=501)$. The participants descriptions as $74.7 \%$ male $(\mathrm{n}=374)$ and $25.3 \%(\mathrm{n}=127)$ were female. The average age of the respondents was 31.5 years.

\section{Measures}

- Psychosocial adjustment skills: psychosocial adjustment skills are conventional to be critical for teammate success. We have taken six items from job performance dimensions subscale (Ferris and Witt, 2001), as social ability adjust in a teamwork environment is necessary to achieve embedded teamwork and task work acquisition. Behavioural control and demonstration of social skills to get adjusted and helping other for accommodating their acts according to team requirement are essential for the team embeddedness. The reliability analysis produced high alpha coefficient for the six items internal consistency $(\alpha=.950)$.

- PADW: stressful situation at workplace gauged by the six items taken from the subscale of BDI (Lovibond, 1995) to identify relationship between the negative affect conditions (Lovibond, 1995) and aptness to adjust their behaviours in accordance with the situation at job performance (Ferris and Witt, 2001). The inter-item reliability and internal consistency were found $(\alpha=.937)$. Individualism in task acquisition: indicator items of perceptual and collaborative conflict management style (CCMS), indicator items for satisfaction with decision-making process taken from CCMS to analyse the homogeneity and heterogeneity of task orientation and acquisition in the team (Paul, 2004). The inter-item reliability and internal consistency alpha coefficient for five items were found $(\alpha=.897)$. 
- PADT: individualism, interpersonal influence and adjustment goals measured by the five items selected from the circumplex scale of interpersonal values (Locke, 2000). Respect is an important variable for the adjustment in any team, therefore participants used a five-point scale, ranging from 1 strongly disagree to 5 strongly agree, to rate the importance of the variable. These five items comprised the PADT aggregate and reflected the adjustment disorder in the team. We conducted EFA on the raw scores of all items to categorise the items related to PADT that loaded on the same factor. The inter-item reliability and internal consistency alpha coefficient for five items were found $(\alpha=.935)$.

- Team leader experience and qualification: this variable was gauged by four items 'I feel very confident about the skills of my team leader', 'my team leader had much knowledge about the project', 'my team leader is well-qualified', and 'I could rely on my team leader' taken from the subscale of paradox and performance (Denison, 1995). The inter-item reliability and alpha coefficient for four items was $(\alpha=.874)$.

- TECN: TECN measured on five items subscale and inter-item reliability was $(\alpha=.931)$. Inter alia 'team members confronted each other on personal matters', and 'my team members disagreed over solutions proposed' items suggested to identify the degree of harmony between team members on consistently work method disagreement.

- Competence development and teamwork embeddedness: competence development and teamwork embeddedness are cardinal factors and proportionate to achieve a collective task. Four items each for CODT and NTEB were taken from occupational well-being (OWSS) model by Saaranen et al. (2006). CODT measured on four items subscale and Cronbach's alpha was reported $(\alpha=.912)$ and NTEB also measured on four items and reliability was $(\alpha=.872)$.

- TAAD: TAAD measured by four items retrieved from DWECS subscale for possible predictors of depression and anxiety (Wieclaw, 2008). The reliability analysis produced high alpha coefficient for the four items internal consistency $(\alpha=.902)$. Item reliability, construct reliability and AVE of the measurement model indicates that the convergent validity is satisfactory, and thus the hypothesised measurement model is reliable for further examination of structural relationships among the constructs (Rajesh and Saravanan, 2018).

\section{Procedure}

The straightforward approach adopted as all eligible participants who provided complete and explicit data were analysed by means score of principal components and CFA on $\alpha=0.05$ significance criterion. Descriptive study and regression analysis were employed to check and test all variable details and hypotheses for adequacy and validation. Correlations to identify the degree of relationship between variable also gauge to infer logical results. Additionally, the test of $\chi^{2}$ was employed to test significance by comparing empirical covariance and adequacy was verified by NFI, RMSEA, CFI, and GFI. Parameters and other statistics estimated by using SPSS and AMOS version 22. 


\section{Results}

\subsection{Descriptive statistics}

The socio-economic and demographic summary of the all qualified participants is shown in Table 1. Items statistics yielded significant positive correlations between various factors. The Pearson product-moment correlation coefficient caused that PADT is significantly and positively correlated with TECN as $\mathrm{r}(501)=.517, \mathrm{p}<.01)$; and TECN with TAAD was $\mathrm{r}(501)=.589, \mathrm{p}<.01)$. All correlation results are shown in Table 2 . The Cronbach's alpha of all items included was found $(\alpha=.951)$.

Table 1 Descriptive*

\begin{tabular}{|c|c|c|}
\hline Variables & Frequency & Percent \\
\hline \multicolumn{3}{|c|}{ Gender of participants } \\
\hline Male & 374 & $74.7 \%$ \\
\hline Female & 127 & $25.3 \%$ \\
\hline \multicolumn{3}{|l|}{ Year of service } \\
\hline 1 to $3 y$ & 82 & $16.4 \%$ \\
\hline 3.1 to $6 y$ & 238 & $47.5 \%$ \\
\hline 6.1 to $10 \mathrm{y}$ & 97 & $19.4 \%$ \\
\hline 10.1 to $20 \mathrm{y}$ & 54 & $10.8 \%$ \\
\hline Above $20 y$ & 30 & $6.0 \%$ \\
\hline \multicolumn{3}{|c|}{ Monthly fixed income } \\
\hline $15 \mathrm{k}$ to $25 \mathrm{k}$ & 197 & $39.3 \%$ \\
\hline 25.1 to $35 \mathrm{k}$ & 148 & $29.5 \%$ \\
\hline 35.1 to $55 \mathrm{k}$ & 80 & $16.0 \%$ \\
\hline 55.1 to $75 \mathrm{k}$ & 1 & $0.2 \%$ \\
\hline $75 \mathrm{k}$ and above & 75 & $15.0 \%$ \\
\hline \multicolumn{3}{|l|}{ Chronological age } \\
\hline $21-30$ & 302 & $60.3 \%$ \\
\hline $31-40$ & 140 & $27.9 \%$ \\
\hline $41-50$ & 39 & $7.8 \%$ \\
\hline $51-60$ & 20 & $4.0 \%$ \\
\hline \multicolumn{3}{|l|}{ Marital status } \\
\hline Single & 392 & $78.2 \%$ \\
\hline Married & 89 & $17.8 \%$ \\
\hline Other & 20 & $4.0 \%$ \\
\hline \multicolumn{3}{|c|}{ Adjustment disorder cases (12-months) } \\
\hline Yes & 180 & $36 \%$ \\
\hline No & 321 & $64 \%$ \\
\hline Total & 501 & $100 \%$ \\
\hline
\end{tabular}

Notes: *Socio-economic and demographic characteristics of the participants. $\mathrm{k}=$ thousand rupees and $\mathrm{y}=$ years. 
Table 2 Correlations and Cronbach's alpha

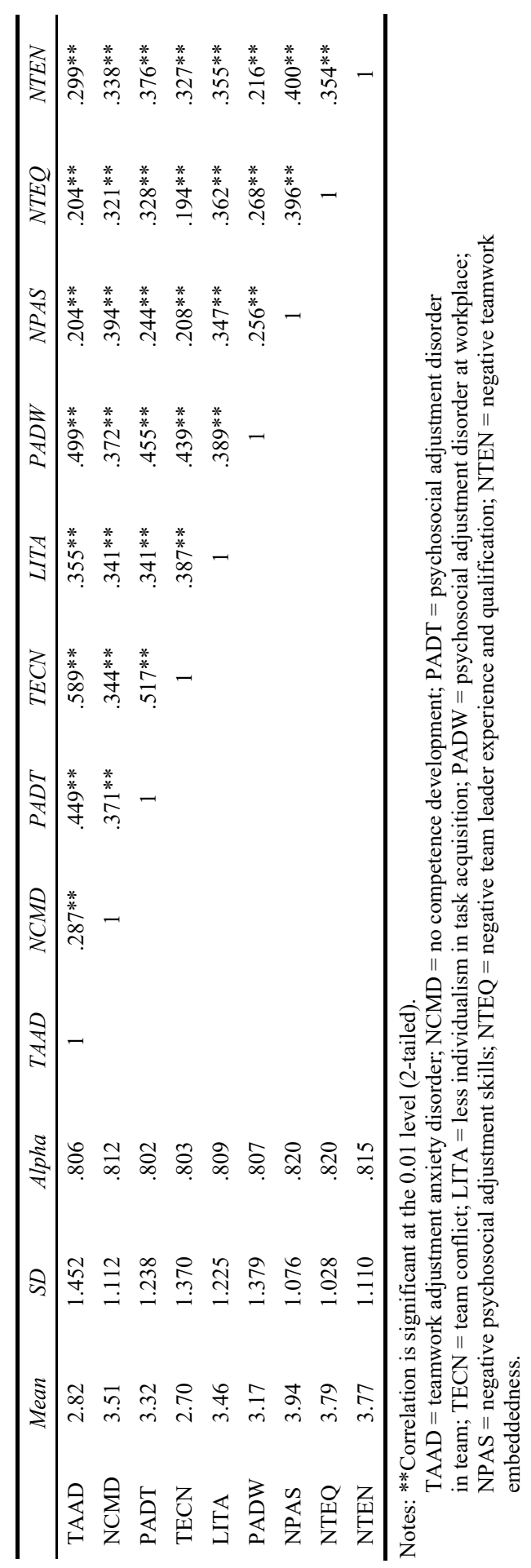


To reduce and structure detection of variables PC analysis, utilising varimax with Kaiser normalisation rotation method was employed to identify variables from the coherent independent subset. The factorability of the items was examined and the analysis of data extracted from heavy loadings, exploratory factors also measured by confirmatory factor analysis. The Kaiser-Meyer-Olkin (KMO) measure of sampling adequacy was .901 and Bartlett's test of sphericity was significant $\left(\chi^{2}(903)=21,082.02, p<.01\right)$ and the commonalities were all above .7. Every item shares some common variances and each indicates that factor analysis was deemed to be suitable with all items. The structural equation model produced significant results (Figure 2) as the $\chi^{2}$ test $(99.374, \mathrm{df}=26$, $\mathrm{p}<.01)$ and its adequacy was examined with indexes $\mathrm{GFI}=.958, \mathrm{CFI}=.942, \mathrm{TLI}=.919$, RMSEA $=.057$ and PCLOSE $=.004$. The SE of the default model was .058 and $\mathrm{CR}=8.207$. Model values fully supported the significance and suitability.

Figure 2 Model values (see online version for colours)

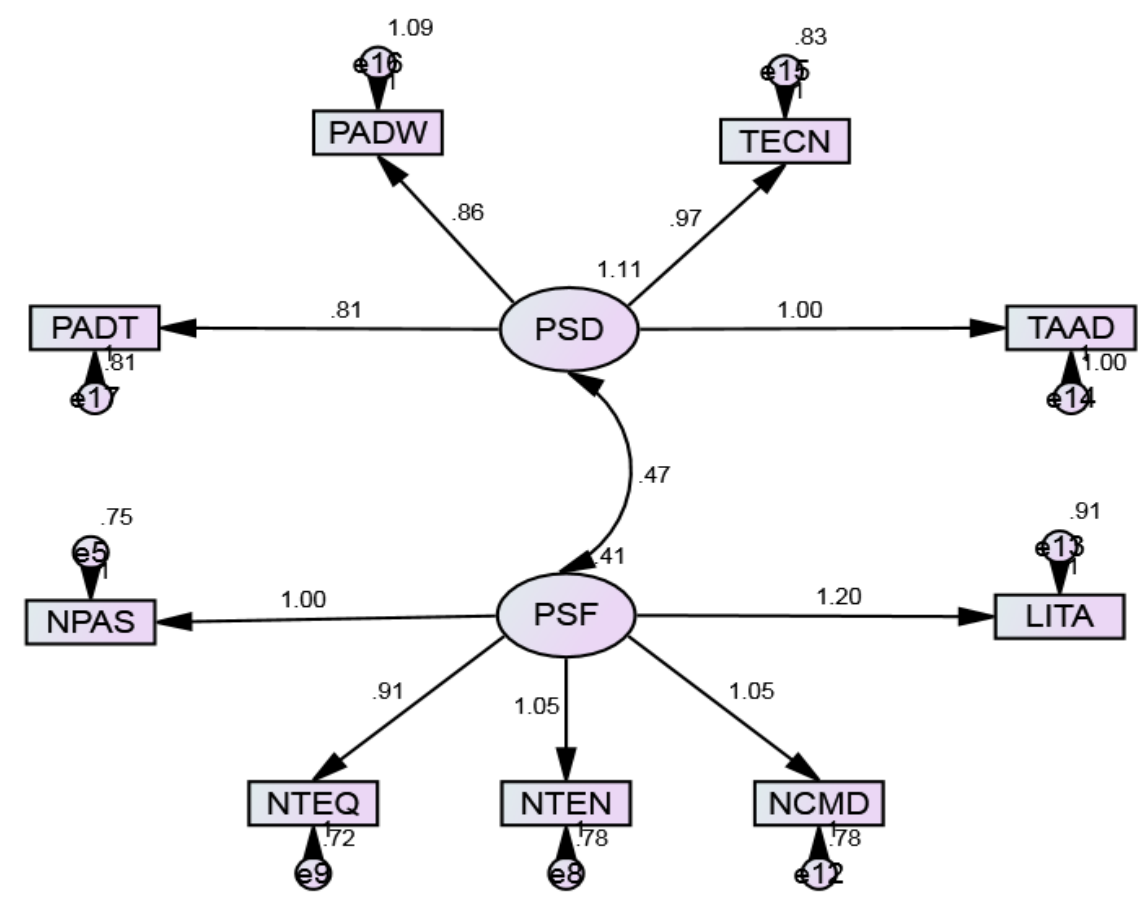

The result indicates that experience effects on TAAD with $\chi^{2}=147.3(96), p=.001$ significantly. Employees having vast experience have a low degree of teamwork adjustment disorder and their frequency are far lower than newly inducted employees in the team.

$71 \%$ employees having vast experience to work in teams received all of the satisfactory conditions in the team, $16 \%$ feel expectations are not met and $13 \%$ were unsatisfied with team composition, TECN, team leader efficiency and individuals' recognition.

Ordinal regression (logit function linked) revealed that no demographic and socio-economic variables were associated with the education and marital status (see Table 4). Participants who did not have a teamwork adjustment disorder were more likely 
to have received the individualistic recognition in teamwork than those who had 12-month teamwork adjustment disorder $(\mathrm{P}=0.021)$.

Table 3 Dependent variable: teamwork adjustment disorder

\begin{tabular}{lcc}
\hline & Model 1 & Model 2 \\
\hline Sum of squares & 449.844 & 457.438 \\
$\mathrm{df}$ & 3 & 8 \\
Mean square & 149.948 & 57.18 \\
$\mathrm{~F}$ & 123.289 & 47.133 \\
Sig. & .000 & .000 \\
Sum of squares & 604.47 & 596.877 \\
$\mathrm{df}$ & 497 & 492 \\
Mean square & 1.216 & 1.213 \\
Sum of squares & $1,054.314$ & $1,054.314$ \\
B & 308 & 044 \\
$\beta$ & .115 & 0.95 \\
Std. error & .114 & .244 \\
$\mathrm{t}$ & 1.99 & .180 \\
Sig. & .046 & .030 \\
\hline
\end{tabular}

In Table 2, the correlations of overall factors contributed towards TAAD are presented and there were positive correlations observed between lack or NCMD, PADT, TECN, LITA, PADW, NPAS, poor and lack of team leader experience and qualification even negative, NTEN and TAAD. Compared with those who did not have a 12-month adjustment disorder cases, participants with the history of adjustment disorder cases were more likely to need competence development programs and recognition on the individual level for team embeddedness at a workplace.

Table 4 Ordinal regression (Logit. function)

\begin{tabular}{|c|c|c|c|c|}
\hline \multicolumn{5}{|c|}{ Model fitting information } \\
\hline Model & -2 log likelihood & Chi-square & $d f$ & Sig. \\
\hline Intercept only & 434.231 & & & \\
\hline Final & 417.788 & 16.442 & 7 & 0.021 \\
\hline \multicolumn{5}{|l|}{ Goodness-of-fit } \\
\hline & & Chi-square & $d f$ & Sig. \\
\hline Pearson & & 147.699 & 305 & 0.448 \\
\hline Deviance & & 114.168 & 304 & 1 \\
\hline \multicolumn{5}{|c|}{ Pseudo R-square } \\
\hline Cox and Snell & 0.032 & & & \\
\hline Nagelkerke & 0.032 & & & \\
\hline McFadden & 0.006 & & & \\
\hline
\end{tabular}




\section{Discussion}

The results of our study provide support for all hypotheses. Hypotheses containing different factors and all such factors divided into two groups PSD and PSF; however, we examined all hypotheses separately and analysed their effect and coherence. Our results shown expected outcome due to the categorical nature of the variables. Factor analysis of data extracted heavy loading and exploratory factors also measured by confirmatory factor analysis because the factors and their pattern of loadings are determined prior to the data analysis and closely associated with the tendency to see variables as hypothetical rather than real latent variables and uniformly regarded as authentic (Bollen, 2002). Our hypotheses based on various assumptions and $\mathrm{H} 1$ posited that psychosocial adjustment disorder significantly correlated with PSF. The review of related literature revealed that attaining the social skills is part of learning and training. This is not necessarily that every person has social skills to influence his/her conditions as "People social skill is distinct from personality, personality and social skill are a quite different personality are relatively stable and enduring whereas social skills are relatively trainable" [Ferris and Witt, (2001), p.1076]. Therefore, testing of this big phenomenon at the workplace was necessary and as result shown in Figure 2 and Table 4 which is significantly correlated and results fully supported our hypothesis. Whereas, $\mathrm{H} 2$ was based on the assumption that PSF contribute more to the PADT.

This assumption confirms that PSF like lack of competence development approach (NCMD), TECN, rejection or unrecognition of individualism in task acquisition (LITA), NPAS, lack of team leader experience and qualification (NTEQ) and crumbled teamwork (NTEN). The results of bivariate correlation and regression analysis supported our hypotheses.

$\mathrm{H} 2 \mathrm{~b}$ posited that PSF significantly contribute to the prediction of increased TECN. We observe and analyse that proves the veracity of this phenomenon and so our results indicated in Tables 2 and 3. The team consists on heterogeneous nature are usually strong on CCMS seem to perform better than their homogeneous counterparts and these teams have a significant number of members who prefer to work with others and who value group interests more than their personal needs (Ferris and Witt, 2001). H2c posited that PSF significantly correlated with TAAD and this indicated in our structural equation model where PSD and PSF significantly and positively related as shown in Figures 1 and 2. The relationship among variables may reflect the homogenising effect of PSF and team embeddedness.

Similarly, H2d, PSF contributes more to the NPAS as PSF coherent with the adjustment disorder and clinical results also confirms that the interaction effects were significant even after controlling for demographic variables and H2e posited that PSF contribute more to the prediction of individualistic task acquisition are fully supported by the statistical analysis of the participants responses as shown in Tables 2 and 3 and Figure 2. Individualistic task acquisition is widely depending on the PSF ontogenesis develops during the teamwork task acquisition due to the emergence of PSF. This increases or decreases depending on the stages of maturity in task acquisition processes. While several scholars have documented differences in various emotional phenomena between individualistic and collectivistic contexts. Although articulating diverse views on the task and attempting to understand others' perspectives which play a crucial role in augmenting group performance (Ferris and Witt, 2001). 
Results and Pearson product moment correlations and regression analysis supported assumption as mentioned in Tables 1 and 2. Although articulating diverse views on the task and attempting to understand others' perspectives, members of heterogeneous groups seem to enrich the collective understanding which plays a crucial role in augmenting group performance.

\section{Limitations, contribution and directions for future research}

Our study has the number of limitations and produced some important directions for future research as this study envisages novel issue of team embeddedness and adjustment disorders. This study also identified that psychosocial adjustment factors have significant influence on team embeddedness at workplace and there are very significant relationship exists between adjustment disorder and team successes or embeddedness.

Whereas, our study restricted to some sugar mills population which operates averagely 120 days in a year and having a diversified pattern of work, therefore, linking of interpersonal interests and desired effect at the workplace may be limited, it would be important to examine these links longitudinally within subjects. We focused on our regional cultural contexts. We identified two conspicuous limitations in this study. First, our measure of social skill is relatively novel, and thus, despite modest efforts to substantiate its construct validity; it has not been subjected to the long-term evaluation process essential to ensure its adequacy. Second, our sample was somewhat modest in size and constrained with respect to the variety of occupations chosen.

It certainly would have been preferable to have a larger sample. However, at this preliminary stage of research development, we thought it appropriate to constrict our sample to those operating in similar functions and positions so as to limit the potential confounding effects that may occur when examining workers who have diverse tasks and levels of responsibility. This study determined the early stages of influence and adjustment disorder.

Future studies might examine the ideal affective states associated with different stages of influence and adjustment, and the changes in ideal effect that occur as a function of the specific people individuals are trying to influence or to whom they are trying to adjust. In this study, we evaluate some variables related and exist in our working-class culture and psychosocial adjustment factors are varied due to which people want to feel more positive than negative, we focused on the valuation of positive states. Generally, our findings add significant information concerning teamwork embeddedness with psychosocial adjustment disorder and analysed data based on direct feedback not on clinical history, this will open a new arena for future research in this context. This study adds to an increase in present literature for teamwork embeddedness and psychosocial adjustment factors evaluations and to suggest that arise during the acquisition of teamwork task.

Indeed, this will help to assess the social skills required for the team embeddedness and indicates adjustment cues in the team. In conclusion, our findings suggest that previously observed teamwork and individualist approach differences in negative and positive states are due to influence and adjustment disorders. These findings take us one step closer to understanding the specific teamwork design mechanisms underlying psychosocial differences. Future studies should examine whether our findings hold for other individualistic and collectivistic cultures as our findings are limited to some 
manufacturing working class, so future studies should examine more diverse community sample populations.

\section{References}

Aksom, H. (2017) 'Infused with value? Trajectories, discourses and institutional constructions in beyond budgeting diffusion', International Journal of Management Concepts and Philosophy, Vol. 10, No. 2, pp.199-225.

Anderson, D.D. (1990) Design for Manufacturability, Optimizing Cost, Quality and Time-toMarket, CIM Press, Lafayette, California.

Appelbaum, S.D. (2005) 'The relationship of ethical climate to deviant workplace behavior', Corporate Governance, Vol. 5, No. 4, pp.43-56.

Appelbaum, S.H. (2007) 'Positive and negative deviant workplace behaviors: causes, impacts, and solutions: corporate governance', The International Journal of Business in Society, Vol. 7, No. 5, pp.586-598.

Association, A.P. (2013) Diagnostic and Statistical Manual of Mental Disorders, American Psychiatric Association, Arlington.

Banister, E.W. (1992) 'The changing face of the workplace', International Journal of Industrial Ergonomics, Vol. 9, No. 1, pp.37-52.

Barbara, A.W. and Valerie, N.S. (2014) Relationships in Organizations: A Work Psychology Perspective, Rachel, M. and Helena, C.T. (Eds.), 175 Fifth Avenue New York, US, St Martin's Press LLC, Palgrave Macmillan.

Bartol, T.K., Matthews, G., Sharma, B. and Scott, L.B. (2011) Management: A Pacific Rim Focus \& Connect Plus, 6th ed., McGraw Hill, London.

Blackmon, K. (1998) 'Differences in manufacturing strategy decisions between Japanese and western manufacturing plants: the role of strategic time orientation', Journal of Operations Management, Vol. 16, No. 2, pp.147-158.

Bollen, K.A. (2002) 'Latent variables in psychology and the social sciences', Annual Reviews Psychology, Vol. 53, No. 1, pp.605-34.

Denison, D.R. (1995) 'Paradox and performance: toward a theory of behavioral complexity in managerial leadership', Organization Science, Vol. 6, No. 5, pp.524-540.

Dhir, S. and Shukla, A. (2018) 'The influence of personal and organisational characteristics on employee engagement and performance', International Journal of Management Concepts and Philosophy, Vol. 11, No. 2, pp.117-131.

Donaldson, S.I. and Grant-Vallone, E.J. (2002) 'Understanding self-report bias in organizational behavior research', Journal of Business and Psychology, Winter, Vol. 17, No. 2, pp.245-260.

Ferris, G.R. and Witt, L.A. (2001) 'Interaction of social skill and general mental ability on job performance and salary', Journal of Applied Psychology, Vol. 86, No. 6, pp.1075-1082.

Galperin, B. (2002) Determinants of Deviance in the Workplace: An Empirical Examination in Canada and Mexico, Unpublished doctoral dissertation, (u.d., Ed.).

Henle, C.A. (2005) 'Predicting workplace deviance from the interaction between organizational justice and personality', Journal of Managerial Issues, Vol. 11, No. 2, pp.247-263.

Hofstede, G. (1985) 'The interaction between national and organizational value systems', Journal of Management Studies, Vol. 22, No. 4, pp.347-357.

Jeppesen, T.H. (2006) 'Teamwork and associated psychological factors: a review', Work \& Stress, April/June, Vol. 20, No. 2, pp.105/128.

Khatri, P. and Gupta, P. (2017) 'Empirical evaluation of positive organisational politics: an Indian context', International Journal of Management Concepts and Philosophy, Vol. 4, No. 10, pp.392-404. 
Locke, K.D. (2000) 'Circumplex scales of interpersonal values: reliability, validity, and applicability to interpersonal problems and personality disorders', Journal of Personality Assessment, Vol. 75, No. 2, pp.249-267.

Lovibond, P.F. (1995) 'The structure of negative emotional states: comparison of the depression anxiety stress scales (DASS) with the beck depression and anxiety inventories', Behaviour Research and Therapy, Vol. 33, No. 3, pp.335-343.

Mullen, B. and Copper, C. (1994) 'The relation between group cohesiveness and performance: an integration', Psychological Bulletin, Vol. 115, No. 2, p.210.

Parker, D.S. and Williams, D.H. (1994) Effective Team Working: Reducing the Psychosocial Risks, Her Majesty's Stationery Office, St Clements House, 2-16 Colegate, NR3 1BQ, Norwich.

Paul, S.S. (2004) 'An empirical investigation of collaborative conflict management style in group support system-based global virtual teams', Journal of Management Information Systems, Vol. 21, No. 3, pp.185-222.

Rajesh, K. and Saravanan, D. (2018) 'Applying structural equation model to study the critical risks in business intelligence and analytical system implementation in Indian retail', International Journal of Management Concepts and Philosophy, Vol. 11, No. 2, pp.190-218.

Rashid Ali, B. and Yasmeen Z.J. (2011) 'Career development within SIKA perspective, case study of Sindh, Pakistan', Grass Roots, Vol. 44, No. 9, pp.61-78.

Roach, D. (2017) 21 September [online] http://likeateam.com/15-simple-reasons-teamwork-fails/ (accessed 2/1/2018).

Robert, C. and Wasti, S.A. (2002) 'Organizational individualism and collectivism: theoretical development and an empirical test of a measure', Journal of Management, Vol. 28, No. 4, pp.544-566.

Robinson, S.L. and Bennett, R.J. (1995) 'A typology of deviant workplace behaviors: a multi-dimensional scaling study', Academy of Management Journal, Vol. 38, No. 2, pp.555-572.

Saaranen, T., Tossavainen, K., Turunen, H., Kiviniemi, V. and Vertio, H. (2006) 'Occupational well-being of school staff members: a structural equation model', Health Education Research, Vol. 22, No. 2, pp.248-260.

Silverthorne, C. (2015) Organizational Psychology in Cross-Cultural Perspective, Library of Congress Cataloging-in-Publication Data, New York, US.

Spreitzer, G.A. (2005) 'Musings on the past and future of employee empowerment', Handbook of Organizational Development, Vol, T. (Ed.) Sage, London, Thousand Oaks.

Subba, D. and Rao, M.K. (2016) 'Measuring the differential effects of corporate social responsibility on compassion at workplace: social exchange theory', International Journal of Management Concepts and Philosophy, Vol. 39, No. 9, pp.171-184.

Wharton (2006) Is Your Team Too Big? Too Small? What's the Right Number?, 14 June [online] $\mathrm{http}$ //knowledge.wharton.upenn.edu/article/is-your-team-too-big-too-small-whats-the-rightnumber-2/ (accessed 17 September 2017).

Wieclaw, J.A. (2008) 'Psychosocial working conditions and the risk of depression and anxiety disorders in the Danish workforce', BMC Public Health, Vol. 8, No. 1, p.280. 